\title{
Lívia Barbosa'
}

\section{Apresentação do Dossiê Consumo e Envelhecimento} os dias 21 e 22 de outubro de 2020, foi realizada na Escola Superior de Propaganda e Marketing, no Rio de Janeiro, a décima edição do Encontro Nacional, a sexta do Encontro Luso Brasileiro e a quarta do Encontro Latino-Americano de Estudos de Consumo. O tema central do evento, realizado em formato digital, foi Consumo e Envelhecimento, e contou com quatro palestras de renomadas(os) especialistas na área, do Brasil e do Reino Unido: as pesquisadoras brasileiras, Guita Debert, antropóloga, professora da Universidade Estadual de Campinas, S.P. e Ana Amélia Camarano, demógrafa, pesquisadora do IPEA, e os pesquisadores ingleses, Daniel Miller, antropólogo, professor na University College of London e Frank Trentmann, historiador, professor no Birbeck College, London. As palestras apresentadas naquela oportunidade compõem o dossiê Consumo e Envelhecimento da revista Dialogo com a Economia Criativa.

Coincidentemente, no momento em que escrevia esta apresentação, no dia 21 de janeiro de 2021, recebi, no meu WhatsApp, uma mensagem sobre "envelhecer" e sobre "quem são esses novos velhos". Era uma mensagem sem pretensões acadêmicas, parte de um universo de milhares de outras que circulam pela internet, todas escritas para emocionar quem as lê, anônimas ou assinadas por supostos autores célebres. Elas aterrissam nos nossos celulares, recheadas de frases de efeito e carregadas tanto de otimismo e promessas alvissareiras, "Get older with me. The best is still to come", (Envelheça comigo. $\mathrm{O}$ melhor ainda estar por vir!) como de saudosismos e desconfiança - "A geração de ouro, dos 40, 50, 60 está indo embora"-

\footnotetext{
1 Pesquisadora convidada do departamento de ciências sociais da PUC/RJ, professora da Universidade Federal Fluminense e co-coordenadora do Grupo de Estudos do Consumo do CNPQ. Foi visiting scholar na Universidade de Toquio, Japão, no Kellog Institute for International Studies, da Universidade de Notre Dame, Indiana/EUA, e na University of York, Helsington, Yorkshire/Reino Unido. Autora de livros e artigos no Brasil e no exterior entre os quais se destacam O Jeitinho Brasileiro (1992), Igualdade e Meritocracia (1999), Sociedade de Consumo (2004), Consumo Cultura e Identidade (2006), em co-autoria com Colin Campbell, Rice and Beans (2012), em co-autoria com Richard Wilks entre outros. E-mail: livia.barbosa3@gmail.com
} 
Na mensagem recebida, a questão inicial era: como "nomear" a faixa etária entre 60 e 80 anos? Termos como idoso, velho, terceira idade, melhor idade entre outros pareciam estar em disputa, ao não preencherem mais os requisitos dos "classificados" e do "classificador". Para alguns eles soavam irônicos, para outros preconceituosos e insatisfatórios. Portanto, algum novo termo terá que surgir para nomear a novidade que bate a nossa porta. Mas, quem são essas pessoas que não pararam no tempo, que operam computadores, escrevem e-mails, mandam WhatsApps e falam em celulares como tivessem feito isso durante toda a vida - indaga, em um tom supostamente perplexo, a autora? Embora o texto não ofereça uma resposta conclusiva para as questões que levanta, ao se encaminhar para o final afirma que "a velhice é uma coisa interna." Fraseando de forma diferente a frase anterior, chegamos à popular fórmula sobre a velhice: a "idade está na cabeça de cada um". Ou seja, fica velho quem quer! Sendo assim, cada um de nós é responsável por esta escolha. Será?

Apesar das meias verdades que estas fórmulas de algibeira podem conter, elas estão longe de dar conta das complexidades envolvidas no processo de envelhecimento nos múltiplos contextos em que ele ocorre e que suscitam reflexões sobre o tema.

Estatísticas mundiais indicam com clareza o envelhecimento da população do planeta como um todo, à exceção do continente africano. Segundo os dados demográficos da ONU, a parcela da população com idade superior a sessenta anos tem crescido a taxas maiores do que a população de jovens entre zero e 14 anos. Em 2018, pela primeira vez na história, pessoas com 65 anos ou mais superaram em número as crianças menores de cinco anos no mundo. Mantendo-se a atual situação, em 2050 a porcentagem mais idosa da população deverá ultrapassar a da mais jovem². Ao invés de uma pirâmide para nos representar demograficamente teremos a figura de um trapézio. O Brasil, que sempre construiu uma representação de si mesmo como um "país jovem e de jovens", alcançará essa marca vinte anos antes, em 2030, e terá que repensar a "sua juventude". Segundo a OMS, em 2030 o Brasil terá a quinta população mais idosa do mundo3.

Para além dessa mudança da "representação de si mesmo", nós, brasileiros, ainda temos que lidar com as implicações do fechamento da janela de oportunidade demográfica na sociedade brasileira, prevista para 2023, mas que ocorreu cinco anos mais cedo, em 2018. Para vários especialistas não aproveitamos o nosso bônus demográfico e perdemos a oportunidade de nos tornarmos um país rico antes de envelhecermos. Continuamos com uma população com baixo nível educacional, atendimento de saúde precário, baixa produtividade e, profundamente, desigual em todos os aspectos.

O fato de estarmos vivendo mais é consequência de vários fatores, tais como o aumento da expectativa de vida, tanto ao nascer como nas idades mais avançadas, trazida pelo desenvolvimento científico, pelas políticas públicas de saúde e pelo de-

\footnotetext{
$2 \quad$ United Nations Organization. The World Population Prospect, 2019.

3 https://jornal.usp.br/atualidades/em-2030-brasil-tera-a-quinta-populacao-mais-idosa-do-mundo/
} 
senvolvimento da medicina. Este aumento da longevidade veio acompanhado pelo declínio nas taxas de natalidade, consequência das técnicas e políticas de controle da natalidade, do movimento feminista, do aumento do nível educacional e da urbanização entre outras.

Não estamos apenas vivendo mais, estamos também vivendo melhor, pelo menos em algumas regiões geográficas do mundo e do Brasil. $O$ envelhecimento, embora seja uma experiência universal, um processo natural inescapável ao qual nenhum indivíduo ou grupo pode evitar, a única outra opção é a morte, na prática ele pode ser vivenciado de formas bastante distintas, como já observava Cícero, há mais de mil anos, no seu famoso discurso sobre a velhice ${ }^{4}$.

A possibilidade de múltiplas formas e vivências de envelhecimento remete-nos novamente ao conteúdo da mensagem veiculada pelo WhatsApp. O que ela quer anunciar e propagar é a existência de um novo significado de ser velho e da velhice no mundo contemporâneo, por isso a interrogação "perplexa" da autora acerca de "quem são essas pessoas e como nomeá-las?".

Estaríamos migrando de uma visão negativa da velhice, caracterizada como um conjunto de perdas - física, social, cívica, e emocional, entre outras - para outra na qual predominam ideias de lazer, prazer, atividade e sociabilidade? Ao que tudo indica sim! Nesta nova versão, envelhecer não significa mais faltas, carências, decadência e dependência, mas presenças positivas como disposição de aprender, autonomia, independência, otimismo, curiosidade, ousadia e participação. Certamente, essas transformações não ocorreram de forma súbita, nos últimos anos. Do ponto de vista histórico, elas começaram a se delinear no início do século XX nos Estados Unidos, a partir de onde se espalharam, de forma desigual, tanto na forma como no ritmo, pela Europa, Japão e demais países. Subjacentes a elas encontram-se tanto a expansão da cobertura de seguridade social para o idoso, que quebrou o elo entre envelhecimento e pobreza, fornecendo as bases para a independência e a autonomia das pessoas em processo de envelhecimento, como uma mudança nos valores e nas políticas públicas e institucionais, que enfatizam a ideia de uma velhice ativa e cidadã.

As implicações dessas transformações para o consumo são expressivas, embora passem despercebidas para a maioria das pessoas que associa velhice à frugalidade ou, no máximo, a consumo de serviços médicos. A velhice ativa vem modificando os mercados de vários produtos e serviços - cultura, lazer, esportes e atividades físicas e turismo são alguns deles - e criando outros, ao mesmo tempo que "inspiram" novas formas de comunicação, de reconhecimento social e de ativismo político.

Este novo contexto, contudo, não neutraliza as fragilidades que acompanham o envelhecimento nem os preconceitos, nem as desigualdades econômicas e sociais que o circundam. Estes continuam a existir e demandam mais do que nunca nossa atenção, para não serem perdidos de vista na ideia de que "só fica velho quem

$4 \quad$ Marco Túlio Cícero, foi um filósofo e famoso orador romano que viveu entre os anos 106 a 43 AEC. Escreveu "Catão, o velho, ou diálogo sobre a velhice", no qual faz uma reflexão surpreendente e equilibrada sobre a velhice, contrastando-a com a juventude. Envelhecer não seria apenas enveredar em um mundo de faltas, perdas e carências, mas adquirir virtudes. 
quer". Um rápido olhar, por exemplo, sobre as diferenças de longevidade entre as pessoas com mais de 60 anos que se declaram brancas e as que se declaram pardas e negras são expressivas e falam por si mesmas 5 . Pelos dados de concentração e desigualdade de renda o Brasil é um daqueles casos em que envelhecer está mais para quem pode do que para quem quer.

A articulação entre consumo e envelhecimento promovida como tema do $X$ ENEC, abre espaço para refletirmos sobre algumas destas questões, tanto no que concerne ao Brasil como em diferentes sociedades; tanto de um ponto de vista histórico como contemporâneo, trazendo à tona as múltiplas e complexas formas de vivenciarmos o processo de envelhecimento e suas implicações. Food for thought para todos nós.

As quatro palestras que compõem esse dossiê foram transcritas e, posteriormente, editadas pelos autores. Elas estão apresentadas na mesma ordem em que ocorreram no evento e mantiveram, sempre que possível o tom e o fluxo de seus respectivos formatos orais originais.

Golden girls and silver surfers: a descoberta do consumidor sênior no século $\mathbf{X X}$, proferida por Frank Trentmann, analisa o desenvolvimento histórico do idoso como consumidor e tem como questão central explicar como esse segmento populacional se tornou um dos maiores da sociedade de consumo contemporânea.

Segundo Trentmann, esta foi uma "transformação massiva" que começa a se delinear primeiramente nos Estados Unidos, no início do século XX e já se encontrava em pleno vapor, naquele país, nas décadas de 1950, 1960 e 1970 e consolidando-se na Europa e no Japão apenas na década de 1980.

Mas quais as raízes destas transformações? Para o autor, elas foram o resultado da combinação de políticas públicas voltadas para o idoso, assentadas em valores veiculados de forma institucional, juntamente com a expansão do sistema de aposentadoria. Este propiciou a oportunidade aos idosos de terem tempo livre conjugado a uma renda. Porém, mais do que tempo livre, sua principal vantagem foi tornar os idosos independentes de filhos e netos e poderem exercer, na prática e de forma efetiva, suas opções de consumo, argumenta Trentmann. Na década de 1950, por exemplo, um em cada três idosos norte-americanos já vivia sozinho, por escolha própria, ao invés de com a própria família, sendo assim senhor/senhora de suas escolhas de consumo.

Além do fator econômico, observa-se, nos Estados Unidos, um tipo de "abraço cívico", nas palavras do autor, em torno do tema de um "envelhecimento ativo", que não envolvia só consumo de lazer, mas, igualmente, cidadania, e se materializava em políticas em relação aos idosos. O argumento por trás desse "abraço cívico" seria a valorização da experiência do idoso, que poderia continuar contribuindo com a vida comunitária cívica. Portanto, as sociedades deveriam cuidar de mantê-los ativos e não colocá-los "na prateleira". Além disso, estas políticas invocavam, também,

$5 \quad$ Ver Flavia Oliveira. Envelhecer é para poucos. O Globo, 5/02/2021; Jose Eustáquio Alves. Apesar do Coronavírus as tendências do envelhecimento populacional vão continuar. https://www.portaldoenvelhecimento.com.br/ apesar-do-coronavirus-as-tendencias-do-envelhecimento-populacional-vao-continuar/. 
razões de ordem prática. Por exemplo, quando o país entra em guerra, e os jovens saem de casa para lutar, se faz necessário que os idosos se mantenham ativos na comunidade, cuidando e mantendo-a viva.

Portanto, consumo, em meados do século XX, nos Estados Unidos, não significava unicamente a aquisição de bens e serviços, era uma parte integrante da cidadania. Assim, "um cidadão ativo implicava em um consumidor igualmente ativo"!

Reconhecendo que o aparecimento das golden girls e dos silver surfers é uma realidade restrita apenas a certas partes do mundo, e considerando as profundas desigualdades que predominam nas demais, Frank Trentmann se interroga sobre o futuro desse "consumidor idoso ativo". Ao analisar os tipos de aplicações financeiras dos fundos de pensão dos trabalhadores e as consequências econômicas e sociais oriundas da epidemia de COVID 19, que já começam a afetar profundamente muitas atividades econômicas, redesenhando algumas ou mesmo extinguindo outras tantas, o autor conclui: "se olharmos para trás pode ser que o último século (que se estende de 1930 a 2019) tenha sido um momento histórico particular que tenha entrado em declínio".

Envelhecimento e consumo: o que mudou com a pandemia?, de Ana Amélia Camarano, interroga o impacto da epidemia de COVID 19 na mudança do regime demográfico e no consumo da população de idosos no Brasil. Embora afirme que só tenha perguntas sobre o tema e não respostas Ana Amélia sugere reflexões importantes de assinalar. Primeiro, o novo/novíssimo normal demográfico, datado de outubro de 2020, indica a diminuição de 1, 4 anos na expectativa de vida das pessoas com mais de sessenta anos. Ou seja, ao invés de esperarem viver mais 23.7 anos após os sessenta anos, com esta diminuição, as pessoas poderão esperar viver 22, 2 anos a mais. Esse dado, conjugado aos efeitos da pandemia nos idosos, cujos números até outubro de 2020, no Brasil, indicavam uma diminuição de 0,5\% desta população, e mantendo-se inalterada a projeção de mortalidade por outras causas, nos permite projetar uma diminuição de 1.000000 no número de idosos para 2040.

Um segundo aspecto a ser assinalado é o efeito da reforma da previdência no período de tempo em que as pessoas na "terceira idade" usufruem simultaneamente de renda e saúde, antes de entrarem na "quarta idade", onde as fragilidades físicas começam a aparecer e a afetar a qualidade de vida. Ao que tudo indica a necessidade de se permanecer por mais tempo no mercado de trabalho, para se fazer jus à aposentadoria integral, se traduzirá no encurtamento desse período, com a consequente diminuição de atividades de lazer, esporte, viagens e consumo cultural, por exemplo.

Do ponto de vista exclusivo da pandemia, os idosos seriam o segmento mais afetado, salienta Ana Amélia. Primeiro, pela maior taxa de mortalidade, devido a maior vulnerabilidade ao Coronavírus. Segundo, pelo maior desemprego, consequência da dispensa direta, e do medo de contaminação, entre outros. Terceiro, pelo aumento dos preconceitos já existentes e aparecimento de novos, percebidos pela quantidade de memes que articulam de forma derrogatória a pandemia, a necessidade de isolamento social e a maior vulnerabilidade dos idosos. Quarto, pelo 
aumento da solidão, problema estrutural dessa faixa etária, que se agravou com as recomendações de restrição de movimento e políticas de isolamento social, no contexto das quais por vezes é tênue e difícil de distinguir a linha entre cuidado e controle. E, por fim, a dependência de cuidados, no caso das pessoas frágeis ou dependentes, que será intensificada pela pandemia e que, em alguns casos, poderá se manter de forma permanente, e cuja maior carga repousa nos ombros femininos. Vários outros impactos são levantados por Ana Amélia no que concerne aos efeitos da COVID-19 em segmentos de consumo nos quais o "idoso" é presença importante como lazer, turismo/viagens e atividades culturais entre outras. Mas independentemente de todas estas repercussões negativas, as palavras finais da autora indicam que embora o sonho de viver muito não seja um fato novo na história, a democratização do aumento da longevidade é uma das maiores conquistas do século $X X$.

Aging with smartphones é o título da palestra de Daniel Miller, na qual ele apresenta os resultados da pesquisa Anthropology of Smartphone and Smart Ageing, realizada sob sua coordenação, envolvendo dezesseis meses de trabalho de campo etnográfico, realizado simultaneamente em nove localidades diferentes - Irlanda, Itália, Cameron, Uganda, Brasil, Chile, Al-Quds' ${ }^{6}$, China e Japão - e envolvendo um time de onze antropólogos. O objetivo central da pesquisa foi investigar o impacto dos smartphones na vida de pessoas em processo de envelhecimento, em diferentes sociedades, com atenção particular na utilização das tecnologias de multimídias para a prática de medicina, cuidados e informações sobre a saúde, conhecida como mHealth (Mobile Health).

Para Miller e sua equipe, o smartphone sociologicamente relevante não é o objeto tecnológico concebido pelos seus criadores, mas o que ele chama de Smart from Below, o resultado do conjunto das mudanças que os "consumidores" fazem com e nos próprios celulares. Do ponto de vista metodológico, essa percepção sociológica do smartphone envolveu conhecer intimamente as transformações e adaptações que os participantes da pesquisa implementaram em seus aparelhos, desde o mix dos aplicativos que utilizavam até o conteúdo produzido por eles mesmos, passando pelas mudanças de setting, abandono de e introdução de novos apps, entre outros. Esta investigação profunda, em um objeto tão íntimo e privado como os smartphones, só foi possível pelo estabelecimento de laços de confiança entre pesquisados e pesquisadores, propiciados pela abordagem etnográfica e a permanência prolongada no campo.

A variedade e a riqueza dos "usos" identificados, ou seja "o impacto das pessoas nos smartphones", pode ser melhor compreendida pelos exemplos etnográficos arrolados por Miller, ao longo da sua palestra/texto, e que sedimentam, de forma gradativa, o caminho para a compreensão teórica dos significados do smartphone na sociedade contemporânea e merecem ser destacados. Primeiro, a compreensão do celular como um "lugar onde vivemos", denominado de Transportal Home, e para onde podemos nos retirar a qualquer momento e desempenhar tarefas como se estivéssemos "em casa". Segundo, a relação íntima entre a pessoa e

$6 \quad$ Al-Quds é o nome árabe para a capital da Palestina, Jerusalém. (Nota da apresentadora.) 
o seu smartphone que faz com que um reflita o outro, sendo o smartphone capaz de "estender a pessoa" de várias maneiras, através de dispositivos e aplicativos, denominada de Beyond Anthropomorphism. Terceiro, a permanente presença física do celular junto aos indivíduos provoca uma transformação na relação destes com o mundo, na medida em que estamos sempre aptos a registrá-lo e captá-lo, estabelecendo conexões permanentes entre cada um de nós e o nosso entorno, nomeada de Perpetual Opportunism. Quarto, a capacidade de "cuidar" de alguém, independentemente da distância física em que nos encontramos dela, seja "na mesma rua ou em "Paris", identificada como Care Transcending Distance.

No que concerne ao uso do mHealth, o approach etnográfico utilizado permitiu: a compreensão das desigualdades, oriundas das diferenças educacionais, nas consultas às diferentes fontes de informação sobre saúde disponíveis na internet; a constatação do uso dos smartphones para este fim, bem além do inicialmente imaginado; a "rejeição" aos apps específicos do $\mathrm{mHealth}$ e o uso daqueles com os quais as pessoas se sentiam mais confortáveis, fruto de suas próprias escolhas. Neste contexto, a abordagem smart-from-below deu seus frutos de forma expressiva, como no caso das pesquisas conduzidas por Marília Duques, no Brasil, e por Alfonso Otaegui, no Chile, ressaltando a presença e a potencialidade do WhatsApp na formação de grupos e na integração de profissionais de saúde de forma a permitir uma atuação mais efetiva. Como conclusão, Miller sugere que a abordagem smart-from-below, ao respeitar as escolhas e a criatividade dos usuários propicia a criação de modelos antropológicos alternativos para $\mathrm{mHealth}$, mais efetivos e econômicos, tanto em recursos como em tempo, e mais "respeitosos" com os usuários.

A velhice na propaganda e a ilusão referencial é o título da palestra de Guita Grin Debert. Seu objetivo é analisar como os idosos são representados nos comerciais, chamando a atenção para a ilusão referencial na promoção de bens e serviços, que impõem uma reinvenção do envelhecimento.

Guita Debert começa por encarar o desafio de "encontrar velhos" na propaganda, que segundo um renomado especialista brasileiro no tema declarou, ao longo de uma conversa com a autora sobre a intenção de pesquisa de uma aluna, ser esta uma categoria inexistente. O passo seguinte para Guita foi uma mudança metodológica: qualificar e quantificar a presença dos idosos em peças publicitárias.

Tradicionalmente, além de rara, a presença do idoso em peças publicitárias foi sempre negativa. Essa imagem começa a se transformar, a partir da década de 1980, tanto em termos de frequência como na forma, ao introduzir aspectos positivos na representação do idoso. Essas novas "versões" estavam articuladas a mudanças ocorridas, também, na gerontologia, que passara a enfatizar noções como "enveIhecimento ativo, terceira idade etc., redefinindo essa fase da vida como sendo não só de perdas mas, também, de "ganhos".

Quais seriam as razões subjacentes a esta mudança? Guita Debert considera que tanto a explicação demográfica como a econômica deixam a desejar, na medida em que boa parte dos comerciais que utilizam "personagens mais velhos", os utilizam como estratégia criativa, pois os produtos e serviços anunciados não têm o 
"velho" como público prioritário para os seus produtos. Daí a necessidade, nos alerta, de separar os "velhos da propaganda" dos propriamente ditos.

Valendo-se de exemplos concretos de pesquisas empíricas realizadas envolvendo a produção e a recepção de peças comerciais, nas quais os temas da tecnologia e do sexo são valorizados para ilustrarem esta nova velhice, a autora aponta para a complexidade subjacente às relações entre as lógicas dos produtores e a reação do público alvo. As reações dos participantes de grupos focais de idosos face à "velhice retratada" em diferentes peças publicitárias, como eles as percebem e se percebem, contrasta e surpreende, em alguns casos, os "criativos" das agências de publicidade e pesquisadores. Mais ainda, as reações desses consumidores repercutem entre produtores e organizações de classe, estabelecendo-se uma dinâmica entre ambos, por vezes de enfrentamento, que culmina, ocasionalmente, em retiradas de anúncios, recolocação de peças publicitárias para mídias específicas entre outras atitudes.

De personagem negativo, estereotipado e simplório, os idosos das peças publicitárias de hoje incorporam uma multiplicidade de atributos positivos como autonomia, entusiasmo, independência, subversão e contestação de valores e comportamentos. Essa redefinição da velhice, que apresenta em muitos casos um "jovem idoso", onde o corpo é "pura plasticidade", ancora-se em um processo de "reprivatização do envelhecimento", salienta Guita, no qual os dramas da velhice se tornam uma responsabilidade de cada indivíduo. Alimentação, estilo de vida saudável, formas de lazer e de atividades motivadoras entre tantas outras se tornam a obrigação de cada um para se manter dentro dos parâmetros do "novo paradigma". E, nas palavras da própria Guita, "as perdas próprias do envelhecimento, da velhice, passam a ser vistas como um sinal de descuido, negligência e falta de auto estima." Gabriel Garcia Marques, em Amor em tempos de Cólera, "mostrou como era difícil ser jovem". Hoje, conclui a autora, é difícil ser velho." 